\title{
The associations between organophosphate esters and urinary incontinence in the general US population
}

\author{
Mingjing He ${ }^{1} \cdot$ Kun Jin $^{1} \cdot$ Shi Qiu ${ }^{1}$ Xinyang Liao ${ }^{1} \cdot$ Xiaonan Zheng ${ }^{1} \cdot$ Zeyu Chen ${ }^{1} \cdot$ Jianzhong $\mathrm{Ai}^{1} \cdot$ Lu Yang $^{1}$. \\ Zhongyuan Jiang ${ }^{2} \cdot$ Dan $\mathrm{Hu}^{2} \cdot$ Qiang Wei ${ }^{1}$ (D)
}

Received: 11 January 2021 / Accepted: 23 April 2021 / Published online: 14 September 2021

(C) The Author(s) 2021

\begin{abstract}
Organophosphate esters (OPEs) impact health in many ways. Since its relationship with urinary incontinence remains unknown, we aimed to explore their associations in the US general population. We combined the results of urine specimens test and selfreported urinary incontinence conditions from the National Health and Nutrition Examination Survey (NHANES) 2013-2014 among 2666 participants and then conducted linear regression and logistic regression to analyse associations between log2transformed OPE concentrations and urinary incontinence. We found that $0.92 \%$ of men and $15.74 \%$ of women complained of mixed urinary incontinence (MUI). The concentrations of diphenyl phosphate (DPHP) were significantly correlated to MUI among women when treated as a continuous variable (adjusted odds ratio $(\mathrm{OR})=1.15 ; 95 \%$ confidence interval $(\mathrm{CI}), 1.01-1.31$; $p=0.0369$ ) and as a categorical variable (adjusted $\mathrm{OR}=1.24 ; 95 \% \mathrm{CI}, 1.03-1.49 ; p$ for trend $=0.0245$ ), whereas no positive correlation was found in males. There were no significant associations between the other three OPEs: bis(2-chloroethyl) phosphate (BCEP), bis(1,3-dichloro-2-propyl) phosphate (BDCPP) and dibutyl phosphate (DBUP). The association of DPHP with an increased prevalence OR of MUI in women is a public health concern; future prospective studies are needed to explore its potential mechanism.
\end{abstract}

Keywords Organophosphate esters (OPEs) $\cdot$ Metabolites $\cdot$ Urinary incontinence $\cdot$ Women $\cdot$ NHANES

\section{Introduction}

Organophosphate esters (OPEs) are a group of synthetic chemicals that have been widely used as replacements for brominated flame retardants (Kemmlein et al. 2003) in construction materials, in furniture, and in the outer shells of electronics. They are also known as plasticisers when used in consumer products (e.g. food packages, beverage containers, children's products and cosmetics) (Luo et al. 2020; Mendelsohn et al. 2016). According to national biomonitoring

Mingjing He, Kun Jin and Shi Qiu contributed equally to this work.

Responsible Editor: Lotfi Aleya

Qiang Wei

weiqiang933@126.com

1 Department of Urology, Institute of Urology, West China Hospital, Sichuan University, Chengdu, Sichuan, China

2 Department of Clinical Research Management, West China Hospital, Sichuan University, Chengdu, Sichuan, China data, OPE metabolites are widespread in the USA, at least eight kinds were detected in most participants of a previous study (Jayatilaka et al. 2019), as well as in common dining table food (e.g. meat, vegetables, eggs, dairies and cereals) (Ding et al. 2018). Since OPEs are metabolism-disrupting compounds, exposure to these may affect the thyroid hormone pathway, which is critical for the growth and development of birds and humans. The affected metabolites can alter sex hormone balance and decrease semen quality in men (Farhat et al. 2013; Meeker and Stapleton 2010; Zhang et al. 2016).

Urinary incontinence, one of the most prevalent health concerns confused in adults, contributes to decreased quality of life, especially in older women (Vaughan and Markland 2020). A representative study done in the USA (Dooley et al. 2008) reported that 2,098 (49.6\%) of the 4229 women suffer from urinary incontinence symptoms. Among them, $50 \%$ reported stress urinary incontinence (SUI), $34.3 \%$ reported mixed urinary incontinence (MUI) and $15.9 \%$ reported urge urinary incontinence (UUI). The symptoms or signs of MUI include involuntary loss of urine associated with SUI and UUI. These are both affected by lifestyle and urinary 
habits (Haylen et al. 2010); thus, the mechanism of MUI is complicated. OPEs are metabolism-disrupting compounds which affect the biological activity; we hypothesize that environmental hazardous pollutants, such as OPE metabolites, could increase the risk for MUI. However, no study has provided insight into the connection between the two.

In the present study, we detected several common OPEs in 1525 participants from the National Health and Nutrition Examination Survey (NHANES) 2013-2014. We aimed to determine the correlation between OPE exposure and MUI in the US general population.

\section{Materials and methods}

\section{Study population}

The NHANES has been conducted continuously since 1999 by the National Center for Health Statistics (NCHS) at the Centers for Disease Control and Prevention (CDC). This survey is rigorously and comprehensively conducted to determine the current health and nutritional status of the US general population through interviews and physical examinations. To find the possible link between OPE metabolite exposure and MUI, we analysed data from the 2013-2014 NHANES. Although incontinence data from NHANES 1999-2018 are available, flame retardant metabolite data were only available for random one-third subset of NHANES participants 6 years old and older during 2013-2014. The analytic cohort was restricted to participants with collected urine specimens $(n=$ 2666) who were randomly chosen by the NCHS for OPE analysis, and then participants with complete data on the following four widely distributed OPEs were included: diphenyl phosphate (DPHP), bis(2-chloroethyl) phosphate (BCEP), bis(1,3-dichloro-2-propyl) phosphate (BDCPP) and dibutyl phosphate (DBUP). Pregnant women $(n=12)$ were excluded from the analysis since pregnancy may affect urinary function. We also excluded participants with incomplete urinary incontinence data $(n=507)$ or covariate information $(n=87)$. After these exclusions, there remained a cohort of 1,525 as analytic samples.

\section{Outcomes and measurement of predictors}

The primary outcome, MUI, was determined by participants' response to these questions: (1) 'During the past 12 months, have you leaked or lost control of even a small amount of urine with an activity like coughing, lifting or exercise?'; (2) 'During the past 12 months, have you leaked or lost control of even a small amount of urine with an urge or pressure to urinate and you couldn't get to the toilet fast enough?' and (3) 'How frequently does this occur?' The following questions were ulteriorly used to assess the presence of incontinence: (1)
'Have you leaked or lost control of even a small amount of urine with an activity like coughing, lifting or exercise?' and (2) 'Have you leaked or lost control of even a small amount of urine with an urge or pressure to urinate and you could not get to the toilet fast enough?' Mixed incontinence was defined as answering yes to both questions. The urine specimens were collected and tested by staff members of NHANEs, we selected four urinary biomarkers: DPHP, BCEP, BDCPP and DBUP from them for analysis.

We performed the analysis using Empower Stats, version 2.0. Statistical analysis was conducted following the NHANES analytic guidelines ('National Health and Nutrition Examination Survey. Analytic guidelines, 19992010', 2013). We defined five race/ethnicity groups: (1) Mexican American, (2) non-Hispanic Black, (3) nonHispanic White, (4) other Hispanic and (5) other races based on self-reported data. We calculated the geometric means (GMs) and distribution percentiles for the concentrations of OPEs (in $\mu \mathrm{g} / \mathrm{L}$ ), which were $\log 2$-transformed because they were right-skewed distributed.

\section{Statistical analysis}

We performed the analysis using Empower Stats, version 2.0. Statistical analysis was conducted following the NHANES analytic guidelines ("National Health and Nutrition Examination Survey. Analytic guidelines, 1999-2010', 2013). We defined five race/ethnicity groups: (1) Mexican American, (2) non-Hispanic Black, (3) non-Hispanic White, (4) other Hispanic and (5) other races based on self-reported data. We calculated the geometric means (GMs) and distribution percentiles for the concentrations of OPEs (in $\mu \mathrm{g} / \mathrm{L}$ ), which were $\log 2$-transformed because they were rightskewed distributed.

We calculated the descriptive statistics for the concentrations of OPE metabolites detected among children and adults, including weighted GMs, percentiles and ranges. OPE metabolites with a detection frequency (DF) $\geq 80 \%$ (i.e. DPHP, BDCPP, BCEP and DBUP) were modelled as continuous $\log 2$-transformed-independent variables in separate models as previously specified. To increase statistical power and precision of effect estimates, these concentrations were replaced below the LOD with LOD $/ \sqrt{2}$ for OPE metabolites detected in $\geq 80 \%$ of the study population (Hornung and Reed 1990; Cole et al. 2009). We used sampling weights as well as strata and primary sampling units to account for the selective bias, nonresponse adjustment and oversampling of certain subpopulations. To adjust the urine dilution, we used a traditional creatinine adjustment, wherein the urinary chemical concentration was divided by the urinary creatinine concentration. Furthermore, to control potential confounding caused by compromised kidney function on creatinine excretion, we employed a 'novel creatinine adjustment' of 
covariate-adjusted standardization (Bulka et al. 2017; O'Brien et al. 2016).

$T$-test and chi-square test were used to compare the means and proportions of baseline characteristics. Multivariable logistic regression analysis was used to estimate the impact of OPE metabolites (continuous variables) on MUI. Multivariate models included the crude model, minimally adjusted model (age, race, physical activity, energy intake, education level, marital status, alcohol intake, body mass index (BMI), cardiovascular disease (CAD) score and poverty-income ratio (PIR) were adjusted) and fully adjusted model II ( $\log 10$-transformed urinary creatinine concentrations was further adjusted). Estimates from these linear and logistic regression analyses were considered as the main results. A few additional analyses were also conducted. First, we used tertiles of OPE metabolites as ordinal categorical variables (first to third, setting the first tertile as reference) to examine potential trends in the association. Second, to account for the non-linearity of the MUI, we conducted smooth curve fitting (penalised spline method) and used a weighted generalised additive model. All statistical analyses were conducted using Empower Stats, version 2.0. A two-sided $p$ value of $<0.05$ was considered statistically significant.

\section{Results}

\section{Participant characteristics}

The current study enrolled a total of 1,525 participants: 749 men $(49.04 \%)$ and 776 women $(50.96 \%)$ with weighted mean ages of $46.19 \pm 16.88$ and $45.72 \pm 15.59$ years old, respectively. Notably, $66.41 \%$ of the participants were non-Hispanic Whites, whereas $63.05 \%$ of them reported to be married or living with a partner. MUI complaints were found in $0.92 \%$ of men and $15.74 \%$ of women. The participants' physical activity, education level and other baseline characteristics are presented in Table 1.

\section{OPE metabolite concentrations}

Based on the original results of the NHANES 2013-2014 investigation, only four chemicals (DPHP, BDCPP, BCEP and DBUP) were detected at levels over $75 \%$ among all the included monitoring OPE metabolites. Table 2 illustrates their GMs, distribution percentiles, LODs and maximum values of concentrations. After adjusting for urine dilution using the $\log 10$-transformed urinary creatinine concentrations adjustment, BDCPP had the highest GM, followed by BCEP, DPHP and then DBUP $(0.81,0.80,0.66$ and $0.42 \mathrm{ng} / \mathrm{mL}$, respectively; see Table 2).

\section{Association between OPE metabolite concentrations (continuous) and MUI}

DPHP showed a significant association with MUI (adjusted model I for age, race, physical activity, energy intake, education level, marital status, alcohol intake, BMI, CAD score and PIR); a $1 \mathrm{ng} / \mathrm{mL}$ increase in DPHP was associated with $15 \%$ increased prevalence odds ratio $(\mathrm{OR})$ for $\mathrm{MUI}(\mathrm{OR}=1.15$; $95 \%$ confidence interval $(\mathrm{CI}), 1.02-1.31 ; p=0.026)$. The results after adjustment for $\log 10$-transformed urinary creatinine concentrations (adjusted model II) were consistent with model I $(\mathrm{OR}=1.15 ; 95 \% \mathrm{CI}, 1.01-1.31 ; p=0.0369)$. However, after dividing the participants by gender, only the women group retained the consistent results $(\mathrm{OR}=1.15 ; 95 \%$ CI, $1.01-1.31 ; p=0.0322$ in adjusted model $\mathrm{I}$ and $\mathrm{OR}=1.16$; 95\% CI, $1.01-1.33 ; p=0.0376$ in adjusted model II). In contrast, no statistically significant association was observed between DPHP and MUI in the individual men group. No positive association was observed between BDCPP, BCEP, DBUP and MUI among all participants (Table 3). In the sensitivity analyses, the main results did not change either when we included delivery conditions in the confounding factors $(p$ $<0.05$ for DPHP and $p>0.05$ for BDCPP, BCEP and DBUP; see Supplementary Table 1).

\section{Association between OPE metabolite concentrations (categorical) and MUI}

To further assess the relationship between OPE metabolite concentration and MUI, we converted DPHP concentrations from continuous variables to categorical variables (in tertiles). In adjusted model I, the ORs in the higher tertiles (T2, T3) when compared to the lowest tertile (T1) tended to be higher among all participants $(\mathrm{OR}=1.24 ; 95 \% \mathrm{CI}, 1.03-1.48$; $p$ for trend $=0.0206$ ). After adjustment for $\log 10$-transformed urinary creatinine concentrations (adjusted model II), the OR remained significant $(\mathrm{OR}=1.24 ; 95 \% \mathrm{CI}, 1.03-1.49 ; p$ for trend $=0.0245)$. Similarly, consistent results were found in the women group $(\mathrm{OR}=1.23 ; 95 \% \mathrm{CI}, 1.02-1.49 ; p$ for trend $=$ 0.0283 in adjusted model I and OR $=1.25 ; 95 \% \mathrm{CI}, 1.03$ $1.52 ; p$ for trend $=0.0262$ in adjusted model II). However, no significant OR was found in the men group (see Supplementary Table 2). We did not observe significant outcomes in the other three OPEs (BDCPP, BCEP and DNBP; see Supplementary Tables 3, 4 and 5).

\section{Discussion}

In the present study, we used the 2013-2014 NHANES database, which is considered to be representative of the population of the USA, to explore the correlations between MUI and four OPEs. More women were found to complain of MUI 
Table 1 Baseline characteristics of the study population from the 2013-2014 NHANES cohort

\begin{tabular}{|c|c|c|c|c|}
\hline & $\begin{array}{l}\text { Total } \\
(n=1525)\end{array}$ & $\begin{array}{l}\text { Men } \\
(n=749)\end{array}$ & $\begin{array}{l}\text { Women } \\
(n=776)\end{array}$ & $p$ value \\
\hline Age & $45.72 \pm 15.58$ & $46.19 \pm 16.88$ & $45.72 \pm 15.59$ & 0.0041 \\
\hline Energy intake (kcal) & $2188.71 \pm 1007.00$ & $2518.79 \pm 1108.90$ & $2188.71 \pm 1007.01$ & $<0.0001$ \\
\hline Creatinine of urine $(\mathrm{mg} / \mathrm{dL})$ & $419.30 \pm 176.27$ & $135.53 \pm 80.28$ & $419.30 \pm 176.28$ & $<0.0001$ \\
\hline Race (\%) & & & & 0.4755 \\
\hline $\begin{array}{l}\text { Mexican American } \\
\text { Other Hispanic }\end{array}$ & $\begin{array}{l}9.2 \\
5.96\end{array}$ & $\begin{array}{l}10.37 \\
5.91\end{array}$ & $\begin{array}{l}11.54 \\
5.86\end{array}$ & \\
\hline Non-Hispanic White & 66.41 & 65.37 & 64.33 & \\
\hline Non-Hispanic Black & 10.52 & 9.9 & 9.28 & \\
\hline Other races & 7.91 & 8.45 & 8.99 & \\
\hline Physical activity (\%) & & & & 0.0046 \\
\hline $\begin{array}{l}\text { Less than moderate } \\
\text { Moderate }\end{array}$ & $\begin{array}{l}44.72 \\
10.66\end{array}$ & $\begin{array}{l}41.28 \\
9.84\end{array}$ & $\begin{array}{l}37.84 \\
9.02\end{array}$ & \\
\hline Vigorous & 44.62 & 48.87 & 53.12 & \\
\hline Education level (\%) & & & & 0.1858 \\
\hline $\begin{array}{l}\text { Less than high school } \\
\text { High school or GED }\end{array}$ & $\begin{array}{l}13.26 \\
20.98\end{array}$ & $\begin{array}{l}14.22 \\
22.46\end{array}$ & $\begin{array}{l}15.18 \\
23.94\end{array}$ & \\
\hline Above high school & 65.76 & 63.32 & 60.88 & \\
\hline Marital status (\%) & & & & $<0.0001$ \\
\hline $\begin{array}{l}\text { Married or living with partner } \\
\text { Living alone }\end{array}$ & $\begin{array}{l}63.05 \\
36.95\end{array}$ & $\begin{array}{l}64.72 \\
35.28\end{array}$ & $\begin{array}{l}66.39 \\
33.61\end{array}$ & \\
\hline Alcohol intake $(\%)$ & & & & $<0.0001$ \\
\hline $\begin{array}{l}\text { None } \\
\text { Moderate }\end{array}$ & $\begin{array}{l}71.56 \\
9.22\end{array}$ & $\begin{array}{l}67.2 \\
14.02\end{array}$ & $\begin{array}{l}62.84 \\
18.82\end{array}$ & \\
\hline Heavy & 19.22 & 18.78 & 18.34 & \\
\hline BMI $(\%)$ & & & & $<0.0001$ \\
\hline $\begin{array}{l}<25 \\
\leq 25 \text { and }<30\end{array}$ & $\begin{array}{l}30.66 \\
31\end{array}$ & $\begin{array}{l}27.24 \\
36.91\end{array}$ & $\begin{array}{l}23.82 \\
42.82\end{array}$ & \\
\hline$\geq 30$ & 38.34 & 35.85 & 33.36 & \\
\hline CAD score $(\%)$ & & & & 0.0363 \\
\hline 0 & 63.4 & 64.62 & 62.22 & \\
\hline 1 & 23.34 & 20.75 & 25.84 & \\
\hline 2 & 13.26 & 14.63 & 11.94 & \\
\hline PIR (\%) & & & & 0.7985 \\
\hline $\begin{array}{l}<1.3 \\
\leq 1.3 \text { and }<3.5\end{array}$ & $\begin{array}{l}21.91 \\
38.16\end{array}$ & $\begin{array}{l}21.39 \\
37.88\end{array}$ & $\begin{array}{l}20.87 \\
37.6\end{array}$ & \\
\hline$\geq 3.5$ & 39.93 & 40.73 & 41.53 & \\
\hline MUI (\%) & & & & $<0.0001$ \\
\hline No & 91.53 & 99.08 & 84.26 & \\
\hline Yes & 8.47 & 0.92 & 15.74 & \\
\hline
\end{tabular}

Mean \pm SD for: age, energy intake, creatinine of urine $(\mathrm{mg} / \mathrm{dL})$ compared to men. The GM concentrations of DPHP were relative to MUI among women when treated both as a continuous or categorical variable. This association remained significant after adjustment for potential confounding factors. However, there were no significant associations between the other three OPEs (BDCPP, BCEP and DBUP).

Other health problems linked to OPEs have been reported in many previous studies. However, to the best of our knowledge, this is the first study that explored the associations between OPE metabolites and urinary incontinence. For example, an in vitro investigation showed that OPE toxicity led to higher incidence of mortality and malformation in zebrafish embryos (Tran et al. 2020; Liu et al. 2012). Xu et al. reported that tri-ortho-cresyl phosphate (TOCP), a kind of OPE, leads to hepatocellular injury with elevation of serum aminotransferase levels in mice (Xu et al. 2016). Similarly, Lee et al. also demonstrated that DPHP is significantly associated with uterine fibroids (Lee et al. 2020). Moreover, Meeker et al. found 
Table 2 Detection and distribution of OPE metabolites in urine of the general US population $(n=1525)$

\begin{tabular}{|c|c|c|c|c|c|c|c|}
\hline & & GM $(95 \%$ CI $)$ & $\mathrm{LOD}(\mu \mathrm{g} / \mathrm{L})$ & $\mathrm{p} 25$ & p50 & $\mathrm{p} 75$ & Max \\
\hline \multirow[t]{3}{*}{ DPHP } & Unadjusted & $0.71(0.640 .78)$ & -3.1844 & -1.6439 & -0.4941 & 0.5160 & 6.9773 \\
\hline & Adjusted I & $0.69(0.620 .77)$ & -4.6543 & -1.3001 & -0.6004 & 0.3446 & 6.8138 \\
\hline & Adjusted II & $0.66\left(\begin{array}{lll}0.60 & 0.73)\end{array}\right.$ & -3.4087 & -1.5237 & -0.5347 & 0.4525 & 6.8594 \\
\hline \multirow[t]{3}{*}{ BDCPP } & Unadjusted & $0.88\left(\begin{array}{lll}0.81 & 0.96\end{array}\right)$ & -3.6439 & -1.8365 & -0.5146 & 0.8074 & 6.4741 \\
\hline & Adjusted I & $0.65(0.590 .71)$ & -4.3219 & -1.4792 & -0.5236 & 0.5146 & 6.0845 \\
\hline & Adjusted II & $0.81(0.740 .89)$ & -3.8799 & -1.7149 & -0.5191 & 0.6878 & 6.2913 \\
\hline \multirow[t]{3}{*}{ ВCEP } & Unadjusted & $0.81\left(\begin{array}{lll}0.72 & 0.92)\end{array}\right.$ & -4.0589 & -2.8365 & -1.4739 & -0.2345 & 6.7814 \\
\hline & Adjusted I & $0.74(0.640 .85)$ & -5.3923 & -2.4150 & -1.5146 & -0.4361 & 5.9153 \\
\hline & Adjusted II & $0.80\left(\begin{array}{l}0.70 \\
0.91)\end{array}\right.$ & -4.2831 & -2.6989 & -1.4948 & -0.3159 & 6.4399 \\
\hline \multirow[t]{3}{*}{ DBUP } & Unadjusted & $0.50(0.320 .76)$ & -4.6439 & -3.8365 & -2.1844 & -1.5146 & 1.9672 \\
\hline & Adjusted I & $0.49\left(\begin{array}{lll}0.30 & 0.80)\end{array}\right.$ & -6.5584 & -3.2345 & -2.3520 & -1.6323 & 2.9672 \\
\hline & Adjusted II & $0.42(0.270 .67)$ & -4.9645 & -3.7286 & -2.1687 & -1.5874 & 2.0770 \\
\hline
\end{tabular}

Percentile knots were used for the $\log 2$-transformed OPE metabolite levels. The knots were located at the 25th, 50th and 75th percentiles; units are in $\mu \mathrm{g} / \mathrm{L}$. Adjusted model I for age, race, physical activity, energy intake, education level, marital status, alcohol intake, BMI, CAD score and PIR; adjusted model II for age, race, physical activity, energy intake, education level, marital status, alcohol intake, BMI, CAD score, PIR and log10-transformed urinary creatinine concentrations

that triphenyl phosphate (TPP), another kind of OPE, may be associated with an increase in prolactin and decrease in semen quality in men (Meeker and Stapleton 2010). These previous studies, along with our additional evidence, suggest that OPE metabolites may pose a substantial public health hazard.

MUI can seriously affect one's quality of life by taking the form of stress incontinence, urge incontinence or both (Irwin et al. 2010). SUI is the involuntary loss of urine with increased intra-abdominal pressure or physical exertion (e.g. coughing, jumping and physical exercise), whereas UUI is caused by irritation or loss of neurologic control over bladder contractions. The existing literature identifies much more complex causes of MUI, because it involves striated muscle atrophy, oestrogen status and inappropriate sensory and motor innervation of the bladder. Some ongoing studies are even assessing the role of plasma glucose in MUI. An investigation regarding diabetes and urinary incontinence in 1461 adult women suggested that women with diabetes or impaired fasting glucose had a higher prevalence of MUI than women with normal fasting glucose (Brown et al. 2006).

Fang et al. reported that some OPE metabolites can activate the peroxisome proliferator-activated receptor (PPAR), a master nuclear receptor that regulates lipid metabolism and adipocyte gene expression and may be a key factor for obesity (Fang et al. 2015). Wang et al. found that TPP exposure causes an increase in BMI, liver weight and hepatic steatosis by altering the expression of genes related to lipid metabolism (Wang et al. 2019). Furthermore, a study of 769 women was

Table 3 Multivariate logistic regression of MUI with and without adjustment

\begin{tabular}{|c|c|c|c|c|c|c|c|}
\hline \multirow[t]{2}{*}{ OPE } & & \multicolumn{2}{|l|}{ Total } & \multicolumn{2}{|l|}{ Men } & \multicolumn{2}{|l|}{ Women } \\
\hline & & OR $(95 \% \mathrm{CI})$ & $p$ value & OR $(95 \% \mathrm{CI})$ & $p$ value & OR $(95 \% \mathrm{CI})$ & $p$ value \\
\hline \multirow[t]{2}{*}{ DPHP } & Adjusted I & $1.15(1.02,1.31)$ & 0.0260 & $1.05(0.66,1.67)$ & 0.8224 & $1.15(1.01,1.31)$ & 0.0322 \\
\hline & Adjusted II & $1.15(1.01,1.31)$ & 0.0369 & $0.95(0.53,1.68)$ & 0.8505 & $1.16(1.01,1.33)$ & 0.0376 \\
\hline \multirow[t]{2}{*}{ BDCPP } & Adjusted I & $0.97(0.86,1.11)$ & 0.6956 & $0.88(0.60,1.30)$ & 0.5310 & $0.99(0.86,1.13)$ & 0.8355 \\
\hline & Adjusted II & $0.94(0.82,1.07)$ & 0.3632 & $0.79(0.48,1.27)$ & 0.3267 & $0.95(0.83,1.09)$ & 0.4772 \\
\hline \multirow[t]{2}{*}{ ВCEP } & Adjusted I & $1.05(0.93,1.17)$ & 0.4526 & $0.76(0.51,1.14)$ & 0.1822 & $1.07(0.95,1.21)$ & 0.2528 \\
\hline & Adjusted II & $1.03(0.91,1.16)$ & 0.6290 & $0.69(0.42,1.15)$ & 0.1553 & $1.06(0.94,1.20)$ & 0.3617 \\
\hline \multirow[t]{2}{*}{ DBUP } & Adjusted I & $0.95(0.81,1.11)$ & 0.4982 & $1.24(0.72,2.15)$ & 0.4345 & $0.92(0.78,1.09)$ & 0.3187 \\
\hline & Adjusted II & $0.97(0.83,1.15)$ & 0.7556 & $1.01(0.54,1.87)$ & 0.9798 & $0.96(0.81,1.14)$ & 0.6345 \\
\hline
\end{tabular}

Adjusted model I for age, race, physical activity, energy intake, education level, marital status, alcohol intake, BMI, CAD score and PIR; adjusted model II for age, race, physical activity, energy intake, education level, marital status, alcohol intake, BMI, CAD score, PIR and log 10-transformed urinary creatinine concentrations 
able to identify obesity as an important risk factor for urinary incontinence in Korean women; obesity can impact the vascular system of the pelvic floor, thus affecting detrusor and sphincter muscle functions. In addition, segmental adiposity can increase abdominal diameters as well as intra-abdominal and bladder pressure, resulting in fatigue, weakness of the pelvic floor muscles and impaired bladder control (Han et al. 2006). These connections pose an important question: is it possible that OPE metabolites increase the risk of MUI by regulating the expression of genes related to obesity?

OPE metabolites are regarded as endocrine-disrupting compounds (EDCs), which mimic hormones in the endocrine system and disrupt the physiologic function of endogenous hormones, as well as interfere with energy homeostasis, lipid metabolism and insulin sensitivity. Many EDCs exhibit oestrogenic or anti-androgenic activity; they can either modify the synthesis or actions of oestradiol and testosterone or interfere with their respective hormone receptors (Giwercman and Giwercman 2011). After a review of the literature, we suspect that OPE metabolites increase the risk of MUI by decreasing testosterone levels. In a rat study, pelvic floor muscle atrophy improved after administration of testosterone in an experimentally induced SUI model; this was suspected to be due to the anabolic effect of testosterone on the pelvic floor muscles (Cody et al. 2012) (Mammadov et al. 2011). Moreover, Michelle et al. explored the relationship of serum testosterone levels and urinary incontinence in women and found a positive correlation between low serum testosterone and SUI and MUI risks. In another study, testosterone has been shown to bind androgen receptors located in the pelvic floor muscle and fascia, thus further changing the function of the levator ani (Kim and Kreydin 2018). On average, testosterone levels in adult men are approximately $7-8$ times as great as in adult females, because their more pronounced metabolism causes the daily production to be approximately 20 times greater in males. This is programmed to diminish with age, particularly in postmenopausal women, who are also more sensitive to testosterone (Southren et al. 1965; Torjesen and Sandnes 2004). Perhaps this may be a potential cause for the higher prevalence of urinary incontinence in women.

Our study has the following limitations. First, the laboratory studies of OPE metabolites and urinary incontinence were limited. Because we used a cross-sectional design, even if it was adequately representative of the US population, we cannot conclude a causal relationship between MUI and OPEs without more experimental results or direct evidence. Second, urine was only collected once, and thus the 24-h changes in the components of urine change may have been missed. In addition, a single measurement of OPE could not represent long-term exposure because of the short biological half-lives of OPEs. Finally, urinary incontinence was measured by answers to questions, the results of which could be influenced by subjective factors, unless we use the urodynamic test to confirm the diagnosis of urinary incontinence.

\section{Conclusion}

To our knowledge, this is the first study focusing on the association between urinary incontinence and OPEs among the general US adult population. DPHP was found to be associated with an increased OR for MUI in women, and some directions for further study were included. Due to the public health concern of OPE metabolite exposure, future prospective research is warranted to explore its potential mechanisms.

Abbreviations MUI, Mixed urinary incontinence; UUI, Urge urinary incontinence; SUI, Stress urinary incontinence; NCHS, National Centre for Health Statistics; NHANES, National Health and Nutrition Examination Survey; DPHP, Diphenyl phosphate; BCEP, bis(2chloroethyl) phosphate; BDCPP, Bis(1,3-dichloro-2-propyl) phosphate; DBUP, Dibutyl phosphate; TOCP, Tri-ortho-cresyl phosphate; PPAR, Peroxisome proliferators-activated receptor; EDCs, Endocrine disrupting compounds; PIR, Poverty-income ratio; BMI, Body mass index; CAD score, Cardiovascular disease score; GED, General educational development; DF, Detection frequency; GM, Geometric mean; LOD, Limit of detection; OR, Odds ratio; CI, Confidence interval; US, United States

Supplementary Information The online version contains supplementary material available at https://doi.org/10.1007/s11356-021-14153-5.

Acknowledgements Thanks to the NHANES participants and the staff members for their contribution of data collection and for making the data publicly available.

Author contribution Protocol/project development: MJH, SQ, ZYJ and DH. Data collection or management: MJH, XYL, ZYC and XNZ. Data analysis: MJH, KJ, SQ and ZYC. Manuscript writing/editing: MJH, KJ, XYL and XNZ. Funding: JZA, LY, SQ and QW. Supervision: SQ and QW.

Funding This research was funded by the National key research and development program of China (Grant No. SQ2017YFSF090096), the National Natural Science Foundation of China (Grant No. 81702536, 81770756, 81974098, 81974099), Programs from Science and Technology Department of Sichuan Province (Grant No. 2014JY0219 and 2017HH0063).

Data Availability All data of the current study are in public and available free of charge in the NHANES repository (https://wwwn.cdc.gov/nchs/ nhanes/Default.aspx).

\section{Declarations}

Ethics approval This study was done using Public Data from the NCHS program, NHANES. The data have been de-identified, and it has not been merged or augmented in a way that has compromised the privacy of the participants. Therefore, no further approval was required and the study follows ethical guidelines. 
Consent to participate Not applicable.

Consent for publication Not applicable.

Competing interests The authors declare no competing interests.

Open Access This article is licensed under a Creative Commons Attribution 4.0 International License, which permits use, sharing, adaptation, distribution and reproduction in any medium or format, as long as you give appropriate credit to the original author(s) and the source, provide a link to the Creative Commons licence, and indicate if changes were made. The images or other third party material in this article are included in the article's Creative Commons licence, unless indicated otherwise in a credit line to the material. If material is not included in the article's Creative Commons licence and your intended use is not permitted by statutory regulation or exceeds the permitted use, you will need to obtain permission directly from the copyright holder. To view a copy of this licence, visit http://creativecommons.org/licenses/by/4.0/.

\section{References}

Brown JS, Vittinghoff E, Lin F, Nyberg LM, Kusek JW, Kanaya AM (2006) Prevalence and risk factors for urinary incontinence in women with type 2 diabetes and impaired fasting glucose: findings from the National Health and Nutrition Examination Survey (NHANES) 2001-2002. Diabetes Care 29(6):1307-1312. https://doi.org/10. 2337/dc05-2463

Bulka CM, Mabila SL, Lash JP, Turyk ME, Argos M (2017) Arsenic and obesity: a comparison of urine dilution adjustment methods. Environ Health Perspect 125(8):087020. https://doi.org/10.1289/ ehp1202

Cody JD, Jacobs ML, Richardson K, Moehrer B, Hextall A (2012) Oestrogen therapy for urinary incontinence in post-menopausal women. Cochrane Database Syst Rev 10(10):Cd001405. https:// doi.org/10.1002/14651858.CD001405.pub3

Cole SR, Chu H, Nie L, Schisterman EF (2009) Estimating the odds ratio when exposure has a limit of detection. Int J Epidemiol 38(6):1674 1680. https://doi.org/10.1093/ije/dyp269

Ding J, Deng T, Xu M, Wang S, Yang F (2018) Residuals of organophosphate esters in foodstuffs and implication for human exposure. Environ Pollut 233:986-991. https://doi.org/10.1016/j.envpol.2017. 09.092

Dooley Y, Kenton K, Cao G, Luke A, Durazo-Arvizu R, Kramer H, Brubaker L (2008) Urinary incontinence prevalence: results from the National Health and Nutrition Examination Survey. J Urol 179(2):656-661. https://doi.org/10.1016/j.juro.2007.09.081

Fang M, Webster TF, Stapleton HM (2015) Activation of human peroxisome proliferator-activated nuclear receptors (PPAR $\gamma 1)$ by semivolatile compounds (SVOCs) and chemical mixtures in indoor dust. Environ Sci Technol 49(16):10057-10064. https://doi.org/10.1021/ acs.est.5b01523

Farhat A, Crump D, Chiu S, Williams KL, Letcher RJ, Gauthier LT, Kennedy SW (2013) In Ovo effects of two organophosphate flame retardants-TCPP and TDCPP-on pipping success, development, mRNA expression, and thyroid hormone levels in chicken embryos. Toxicol Sci 134(1):92-102. https://doi.org/10.1093/toxsci/kft100

Giwercman A, Giwercman YL (2011) Environmental factors and testicular function. Best Pract Res Clin Endocrinol Metab 25(2):391-402. https://doi.org/10.1016/j.beem.2010.09.011

Han MO, Lee NY, Park HS (2006) Abdominal obesity is associated with stress urinary incontinence in Korean women. Int Urogynecol J
Pelvic Floor Dysfunct 17(1):35-39. https://doi.org/10.1007/ s00192-005-1356-8

Haylen BT, de Ridder D, Freeman RM, Swift SE, Berghmans B, Lee J et al (2010) An International Urogynecological Association (IUGA)/International Continence Society (ICS) joint report on the terminology for female pelvic floor dysfunction. Neurourol Urodyn 29(1):4-20. https://doi.org/10.1002/nau.20798

Hornung RW, Reed LD (1990) Estimation of average concentration in the presence of nondetectable values. Appl Occup Environ Hyg $5(1): 46-51$

Irwin DE, Milsom I, Chancellor MB, Kopp Z, Guan Z (2010) Dynamic progression of overactive bladder and urinary incontinence symptoms: a systematic review. Eur Urol 58(4):532-543. https://doi.org/ 10.1016/j.eururo.2010.06.007

Jayatilaka NK, Restrepo P, Davis Z, Vidal M, Calafat AM, Ospina M (2019) Quantification of 16 urinary biomarkers of exposure to flame retardants, plasticizers, and organophosphate insecticides for biomonitoring studies. Chemosphere 235:481-491. https://doi.org/10. 1016/j.chemosphere.2019.06.181

Kemmlein S, Herzke D, Law RJ (2003) BFR-governmental testing programme. Environ Int 29(6):781-792. https://doi.org/10.1016/s01604120(03)00112-0

Kim MM, Kreydin EI (2018) The association of serum testosterone levels and urinary incontinence in women. J Urol 199(2):522-527. https:// doi.org/10.1016/j.juro.2017.08.093

Lee G, Kim S, Bastiaensen M, Malarvannan G, Poma G, Caballero Casero N, Gys C, Covaci A, Lee S, Lim JE, Mok S, Moon HB, Choi G, Choi K (2020) Exposure to organophosphate esters, phthalates, and alternative plasticizers in association with uterine fibroids. Environ Res 189:109874. https://doi.org/10.1016/j.envres. 2020.109874

Liu X, Ji K, Choi K (2012) Endocrine disruption potentials of organophosphate flame retardants and related mechanisms in H295R and MVLN cell lines and in zebrafish. Aquat Toxicol 114-115:173-181. https://doi.org/10.1016/j.aquatox.2012.02.019

Luo K, Zhang R, Aimuzi R, Wang Y, Nian M, Zhang J (2020) Exposure to organophosphate esters and metabolic syndrome in adults. Environ Int 143:105941. https://doi.org/10.1016/j.envint.2020. 105941

Mammadov R, Simsir A, Tuglu I, Evren V, Gurer E, Özyurt C (2011) The effect of testosterone treatment on urodynamic findings and histopathomorphology of pelvic floor muscles in female rats with experimentally induced stress urinary incontinence. Int Urol Nephrol 43(4):1003-1008. https://doi.org/10.1007/s11255-0119938-5

Meeker JD, Stapleton HM (2010) House dust concentrations of organophosphate flame retardants in relation to hormone levels and semen quality parameters. Environ Health Perspect 118(3):318-323. https://doi.org/10.1289/ehp.0901332

Mendelsohn E, Hagopian A, Hoffman K, Butt CM, Lorenzo A, Congleton J, Webster TF, Stapleton HM (2016) Nail polish as a source of exposure to triphenyl phosphate. Environ Int 86:45-51. https://doi.org/10.1016/j.envint.2015.10.005

O’Brien KM, Upson K, Cook NR, Weinberg CR (2016) Environmental chemicals in urine and blood: improving methods for creatinine and lipid adjustment. Environ Health Perspect 124(2):220-227. https:// doi.org/10.1289/ehp.1509693

Southren AL, Tochimoto S, Carmody NC, Isurugi K (1965) Plasma production rates of testosterone in normal adult men and women and in patients with the syndrome of feminizing testes. J Clin Endocrinol Metab 25(11):1441-1450. https://doi.org/10.1210/jcem-25-111441

Torjesen PA, Sandnes L (2004) Serum testosterone in women as measured by an automated immunoassay and a RIA. Clin Chem 50(3): 678; author reply 678-679-679. https://doi.org/10.1373/clinchem. 2003.027565 
Tran CM, Lee H, Lee B, Ra JS, Kim KT (2020) Effects of the chorion on the developmental toxicity of organophosphate esters in zebrafish embryos. J Hazard Mater 401:123389. https://doi.org/10.1016/j. jhazmat.2020.123389

Vaughan CP, Markland AD (2020) Urinary incontinence in women. Ann Intern Med 172(3):ITC17-ITC32. https://doi.org/10.7326/ aitc202002040

Wang D, Yan S, Yan J, Teng M, Meng Z, Li R, Zhou Z, Zhu W (2019) Effects of triphenyl phosphate exposure during fetal development on obesity and metabolic dysfunctions in adult mice: Impaired lipid metabolism and intestinal dysbiosis. Environ Pollut 246:630-638. https://doi.org/10.1016/j.envpol.2018.12.053
Xu LL, Long CY, Wang JL, Yu M, Chen JX (2016) Involvement of oxidative stress in tri-ortho-cresyl phosphate-induced liver injury in male mice. Hum Exp Toxicol 35(10):1093-1101. https://doi. org/10.1177/0960327115621363

Zhang Q, Ji C, Yin X, Yan L, Lu M, Zhao M (2016) Thyroid hormonedisrupting activity and ecological risk assessment of phosphoruscontaining flame retardants by in vitro, in vivo and in silico approaches. Environ Pollut 210:27-33. https://doi.org/10.1016/j. envpol.2015.11.051

Publisher's note Springer Nature remains neutral with regard to jurisdictional claims in published maps and institutional affiliations. 